\title{
Socorro! Caí da Boca!: A Cultura dos Detentores de Cargos de Confiança - Um Estudo de Caso
}

\section{Help! I've Lost my Public Office Crushy Job: The Culture of People in Positions of Trust - A Case Study}

\section{Gilson Gil}

Departamento de Ciências Sociais, Universidade Federal do Amazonas, Manaus, Amazonas, Brasil

\section{RESUMO}

O artigo efetua uma análise contextualizada de um segmento dos detentores de cargos de confiança do Governo do Amazonas, abordando suas crenças e valores, verificando alguns dos princípios norteadores de suas ações entre 2011 e 2016. Compreender o pensamento do servidor público é essencial para projetos de reforma administrativa e o debate sobre o papel do Estado no Brasil. A partir deste estudo de caso, futuras investigações poderão ser feitas de maneira mais apropriada, levando em conta as preocupações imediatas desse grupo específico do funcionalismo e interpretando algumas de suas concepções sobre o que seja participar da gestão pública.

Palavras-chave: Administração pública, Cultura, Comportamento.

\section{ABSTRACT}

The article performs a contextualized analysis of a segment of the trust holders of the Government of Amazonas, addressing their beliefs and values, verifying some of the guiding principles of their actions, between 2011 and 2016. Understanding the thinking of the public servant is essential for administrative reform projects and the debate on the role of the State in Brazil. Based on this case study future investigations can be made in a more appropriate way, taking into account the immediate concerns of this specific group of civil servants and interpreting some of their conceptions about what it means to participate in public management.

Keywords: Public management, Culture, Behavior. 


\section{INTRODUÇÃO}

Durante seis anos (2011-2016) fiz parte da administração estadual do Amazonas em diferentes cargos de gestão, tendo sido cedido pela Universidade Federal temporariamente. Estando próximo ao primeiro escalão, em cargos de chefia, assessoria e como secretárioexecutivo, vinculado a setores intermediários da gestão, participei de reuniões e eventos das mais variadas naturezas, transitando por diversos tipos de atividades e instituições. Atravessei períodos de abundância (2011-2014) e de extrema crise econômica (2015-2016). Da mesma forma, vivi épocas de estabilidade política e de crise, o que resultou, inclusive, na saída de um governador (em 2017). Minha posição “intermediária”, entre o acadêmico e o servidor estadual, me fazia enxergar as situações de forma complexa e densa, às vezes, me posicionando como interventor direto nas ações elaboradas, às vezes, vendo-as como elementos para possíveis análises posteriores. Ao longo desse período, respeitando a polifonia desse ambiente (no qual, eu mesmo era parte integrante), procurei dialogar, ouvir opiniões e compreender formas de pensar e agir - formais e informais - sobre a atividade administrativa e o ofício do servidor público. A partir das reflexões de Loic Wacquant, me atreveria a dizer que construí uma "participação observante" (WACQUANT, 2002, p. 23), pois, às vezes, eu quase fui exonerado e, em outros momentos, tinha de elaborar as listas de demissões e contratações, como falarei mais adiante.

Busquei entrar nesse jogo de subjetividades, nessa negociação de visões sobre a realidade, a fim de, consciente dos perigos de tal aproximação e da necessidade de manter a "estranheza da outra voz" (CLIFFORD, 2008, p. 49), interpretar como tais subjetividades compunham essa teia frágil e instável do que se denomina de "serviço público". Levei em consideração problemas como os da "experiência" e da "alteridade" (GOLDMANN, 2006, p. 167), para realizar minha abordagem, identificando e respeitando os limites e possibilidades dela. Pensava em, no dia que saísse e voltasse à atividade acadêmica, escrever artigos que fossem um "relato de uma experiência" (SOARES, 2000, p. 49) pessoal e profissional, transmitindo e analisando parte daquilo que vivenciei. No início, minhas anotações eram direcionadas ao tema do formato estrutural da administração estadual. Pretendia entrar na discussão sobre reforma administrativa no Brasil, verificando quais os impasses de uma "administração pública gerencial" (PEREIRA, 1996, p. 273) que modernizasse o país, incrementasse a eficiência competitiva do Estado e, consequentemente, ampliasse a cidadania, através de uma mudança de nossa supostamente atrasada "cultura burocrática" (PEREIRA, 1996, p. 294). A ideia inicial, que não prosperou, seria discutir modelos de gestão, em um nível macro. Caminhei por outro rumo, desvinculando- 
me do debate estrutural e ficando nos limites, fluidos, de um estudo antropológico da política e das organizações.

Contudo, compreendi que tinha outro tema diante de meus olhos que poderia abrir horizontes distintos de discussão. Notei que os detentores de cargos de confiança possuíam uma maneira própria de entender a sua situação, o papel do governo e a sua função dentro do serviço público. A partir de então, redirecionei meu olhar e minha sensibilidade, atento à dinâmica do poder e da hierarquia dos cargos que eu ocupava e daqueles com quem eu lidava, para a linguagem e as percepções de alguns setores do funcionalismo. Utilizando os termos de uma antropóloga, firmei a convicção de que abordar as “[...] representações e valores atualizados pelos sujeitos em sua prática cotidiana são fundamentais no processo de constituição da vida social" (CHAVES, 2003, p. 16). Os detentores de cargos de confiança, de forma geral, sentiamse como um corpo em separado, mas com dilemas próprios, vendo-se como uma verdadeira irmandade corporativa. Entendi, ao ouvir de um servidor nomeado que um colega não precisava se preocupar com exonerações, "porque ele era de carreira e sempre teria pra onde ir", que havia uma diferenciação simbólica entre esses "dois corpos funcionais [...] ]os permanentes e os nãopermanentes" (PIRES; MACEDO, 2006, p. 97). Tal distinção seria fundamental na construção dessa subjetividade comum aos comissionados, o que passou a ser meu interesse imediato de investigação.

É bom destacar que este artigo analisa somente os nomeados para cargos médios, evitando aqueles do primeiro escalão (os secretários), porque eles possuem outros dilemas e identidades. Também evitei os cargos de menor relevo, pois dificilmente eram afetados por mudanças nas orientações políticas, possuindo relativa durabilidade. Seus dilemas e anseios também eram outros, o que não foi objeto, neste artigo, de reflexão. Assim, a ideia central que se construiu foi entender como pensam e quais os valores que orientam esse grupo funcional (servidores nomeados de escalão médio) na elaboração de sua identidade. Posso definir esse grupo como sendo composto por assessores, consultores, secretários-executivos, secretáriosadjuntos e chefes de departamento e de gabinete. São cargos intermediários, com relativo poder e autonomia, mas que não estão no "primeiro escalão", formado pelos secretários de estado. Também não são os "operacionais", que seriam os nomeados de menor posição hierárquica e que, pela distância dos centros de poder, acabam sendo pouco afetados por mudanças políticas localizadas. Ressalte-se, contudo, que todos esses escalões interagem e formam um conjunto, por mais tênue que seja.

Longe de pensar essas pessoas pelo viés da moralidade, criticando-as como entraves a uma suposta modernização, procurei entender os princípios que seguem e de que forma 
compreendem o mundo organizacional no qual operam. Em vez de dizer como deveriam se comportar, busquei compreender sua conduta diária real. Bezerra (1999), em sua análise sobre a política brasileira, dizia que a abordava “como efetivamente ela é praticada" (BEZERRA, 1999, p. 11). Segui essa trilha, buscando respeitar os depoimentos e percepções dos atores. Procurei respeitar a alteridade envolvida nesses contextos, ciente de todas as suas "manipulações" (AUGÉ, 2014, p. 22) e arbitrariedades envolvidas. Não via esse servidor como um obstáculo "patrimonialista" à construção de um país "moderno", no qual a "representação de interesses" prevalecesse (SCHWARTZMAN, 1982, p. 25). Meu objetivo, na confecção dessas observações, frutos de uma "experiência pessoal" (WACQUANT, 2002, p. 11), com todos seus elementos de intersubjetividade, foi compreender as linhas de raciocínio e os valores que orientam esses nomeados para cargos de confiança, pensando-os como possuidores de um "saber local", ou seja, como indivíduos que agem segundo uma cultura que pudesse ser "tratada como um sistema significativo" (GEERTZ, 2013, p. 13). Minha meta foi, então, esboçar, de forma exploratória, uma "tradução", na qual, nos termos de Clifford Geertz, pudesse explicar "suas estruturas locais de saber" (GEERTZ, 2013, p. 12). Atentei em não reificar as falas dos atores, verificando similitudes e regularidades nas suas ações. O pressuposto seria, seguindo as análises de Silva (2014), de que as representações desses servidores teriam "um papel preponderante nas suas práticas culturais/organizacionais" (p. 247). Compreendi que era um segmento que possuía "suas próprias leis e normas" (DAMATTA, 1985, p. 11). A tarefa, daí por diante, foi buscar decifrar esses significados não escritos e não contratuais, e identificar seus "códigos de conduta", ressaltando que, inclusive, passei por um "processo de aprendizado", o que certas falas, que ouvi em tom de conselho ou advertência demonstram (VIANNA; FARIAS, 2011, p. 87).

Evitei, ao longo do artigo, citar nomes e definir datas, a fim de não criar constrangimentos e personalizar opiniões. Porém, posso mencionar que eles transcorreram entre 2011 e 2016. Nesse período, o mesmo grupo político permaneceu no poder, o que não impediu que mudanças em cargos estratégicos e nas políticas ocorressem. Todas essas mudanças geravam viradas nos cargos e nomeações novas, as quais eram entremeadas de jogadas políticas e reações inusitadas dos atores. Essas reviravoltas ocorriam em meio a um horizonte de um "saber práticoexperiencial" (SILVA, 2014, p. 245), distinto do "saber teórico" dos ocupantes dos cargos formais. Compreender alguns elementos desse "saber prático-experiencial" é um dos objetivos deste artigo. Usei a opção de "ocultar as origens" (BRONZ, 2014, p. 239) dos relatos, a fim de impedir que certos impasses éticos pudessem vir à tona, prejudicando a análise. Nesse sentido, a narrativa não contém nomes de pessoas, empresas ou órgãos, somente o teor de suas reações, 
sentimentos, linguagens e expectativas. Decidi abstrair das "situações empíricas um conjunto de informações" (BRONZ, 2014, p. 237), mas preservando o contexto das relações de poder nas quais se inseriam. Tinha em mente o problema do "anonimato", comum em pesquisas sobre políticos e autoridades, mas, também, ao separar esses segmentos, evitar opor dois mundos “o nós e o eles", prática inadequada nesta análise (BEVILAQUA, 2003, p. 54).

Em termos numéricos, destaco que, em 2011, quando iniciei meu trabalho no governo, eram mais de setenta mil servidores, sendo aproximadamente quatro mil comissionados. Em 2017, já eram cerca de cinco mil cargos de confiança existentes no governo estadual do Amazonas, em um total de 80.560 postos (BRANDÃO, 2017)1 . São cargos de livre nomeação, sem vínculos estatutários com o governo. Em 2019, somente a Casa Civil possuía 538 servidores, sendo 389 comissionados. São cargos que variam de assessor a secretário de estado. Em 2018, a folha salarial consumiu mais de 6 bilhões de reais, ou seja, 48,33\% do orçamento. A importância desse segmento é tão grande que o TCU recomendou, inclusive, que $20 \%$ dos comissionados fossem exonerados para não extrapolar a Lei de Responsabilidade. Com o intuito de aprofundar essa contextualização, ressalto que, no Amazonas, a rotatividade de governadores, desde a redemocratização, é pouca. Apenas cinco foram eleitos pelo voto (Gilberto Mestrinho, Amazonino Mendes, Eduardo Braga, Omar Aziz e José Melo), desde 1982 até 2016, quando estive trabalhando no governo, e todos do mesmo grupo político (FARIAS, 2010). Outro ponto relevante é que a questão partidária pouco importa neste cenário. Esses governadores já frequentaram partidos como Partido do Movimento Democrático Brasileiro (PMDB), Partido democrata Cristão (PDC), Partido Progressista Renovador (PPR), Partido da Frente Liberal (PFL), Partido Popular Socialista (PPS), Partido Republicano da Ordem Social (PROS), Partido da Mobilização Nacional (PMN) e Partido Social Democrático (PSD), sendo apoiados pelos mais diferentes matizes ideológicos, da direita à esquerda. Além disso, sempre tiveram o apoio da maioria dos deputados estaduais e dos prefeitos do interior. O essencial é que sempre foram eleitos os candidatos do governador, aqueles que detinham a "máquina". Aqui, é bom mencionar a atualidade das análises de Leal (2012) sobre o coronelismo, e o compromisso do poder local (municipal) com o central (o governo estadual), que resultou em “máquinas eleitorais estáveis [...] de feição governista" (LEAL, 2012, p. 123). Nesse contexto, fazer a máquina "trabalhar para você", outro termo usado pelos políticos e pela mídia, é algo representado como positivo. Daí, deter muitos cargos sob sua proteção implicaria em um capital

1https://www.acritica.com/channels/manaus/news/amazonino-mendes-herdara-exercito-de-cinco-milcomissionados-no-estado. 
eleitoral de grande valia. Um servidor antigo, há vinte anos em cargos elevados, me advertiu, diante de um conflito, que está "ali há muitos anos, eu já vi de tudo por aqui".

O pressuposto seria, seguindo as análises de Silva (2014, p. 247), que as representações desses servidores teriam "um papel preponderante nas suas práticas culturais/organizacionais". Compreendi que era um segmento que possuía "suas próprias leis e normas" (DAMATTA, 1985, p. 11). Minha tarefa, daí por diante, foi buscar decifrar esses significados não escritos e não contratuais, identificando suas linhas centrais.

Diante de um mundo racionalizado weberiano, com sua dominação racional-legal, em que o predomínio da racionalidade jurídica dominaria a sociedade através da burocracia “[...] com seu caráter racional: meios, regras, fins e objetivos" (WEBER, 1982, p. 282), seria de se supor que o profissionalismo e a impessoalidade atuariam como os valores centrais dessas organizações públicas. Todavia, conforme fui compreendendo, os grupos facilmente se separavam e se reagrupavam, construindo identidades particulares. Eram "outros" que se criavam e recriavam dentro do mesmo ambiente. Essa "participação observante" (WACQUANT, 2002) que comecei compreendia como os indivíduos interagiam em redes, criando e recriando seu universo valorativo, indo muito além dos regulamentos. Era imprescindível “[...] devolver o indivíduo a seu contexto social e observá-lo em suas atividades rotineiras" (WHYTE, 2005, p. 20), caso quisesse superar a abordagem jurídico-legalista sobre esse segmento dos servidores. Assim, o estudo procurou as "práticas administrativas na sua atuação real” (GEERTZ, 1991, p. 80), buscando evitar análises reificantes ou desprovidas do dinamismo que as relações de poder na máquina pública possuem. Evitei, assim, teorizações desvinculadas do cotidiano, ressaltando como a prática dos atores de uma organização continuamente a constrói e descontrói. Recuperando Simmel (1983), pode-se dizer que busquei mostrar como não haveria uma "sociedade absoluta", ou seja, um modelo acabado de relacionamento organizacional, mas uma "extraordinária pluralidade e variedade de formas de interação" (p. 65).

Dessa maneira, para fechar este bloco, creio ser válido ressaltar, com o perigo da ênfase excessiva, que não pretendo entrar no debate sobre o modelo mais "eficiente" de gestão, defendendo ou criticando os concursos ou as avaliações de desempenho, como faz a vertente legalista (FERREIRA, 2014). Por outro lado, delinearei a construção interativa e situacional de conceitos como eficiência, produtividade ou desempenho nesse segmento. Seguindo um autor que se dedica a tema similar, destaco a necessidade de se estudar essa relação entre os burocratas de carreira e os nomeados, em vista de uma maior compreensão do funcionamento do Estado e sua interação com os partidos e seus filiados (LOPEZ, 2015). Antes de serem noções estáticas, pré-definidas legalmente, essas são ideias socialmente elaboradas, cotidianamente vivenciadas 
e reinventadas pelos agentes. Entendo que as organizações, inclusive as públicas, são "entidades vivas, cheias de autorreflexão e consciência" (DAMATTA, 1984, p. 12).

Este estudo pretende, assim, se inserir no debate mais amplo sobre o papel do Estado no Brasil. Ele visa analisar "por dentro" as organizações públicas, a partir de um caso, verificando como certos atores constroem a realidade organizacional na qual se inserem, abordando alguns de seus anseios, expectativas e crenças. Essa abordagem pode ser uma forma de acesso a esse mundo, ajudando-nos a compreender melhor seus princípios e ideias-chave, valorizando os discursos que circulam nas organizações, as relações de poder que as constituem e a construção de verdades e práticas no seu interior, "sem nunca admitir a preexistência de um sujeito" do conhecimento ou de saberes totalizantes (FOUCAULT, 1999, p. 13). É dessa forma que conceitos como "máquina", "clientelismo" ou "personalismo" aparecerão. Frutos de um saber construído internamente, dentro de uma teia significante, mas nunca como ideais normativos congelados. Para fins de exposição, as falas originais dos atores virão entre aspas, facilitando a compreensão do texto.

\section{CONFIANÇA}

Em primeiro lugar, é bom demarcar que a nomeação é o grande momento para esses “escolhidos". Todos, nos mais diferentes níveis, entendem que fazem parte de um grupo seleto, um segmento de indivíduos que possuem “um padrinho". São nomeados, principalmente, por indicação de políticos, interessados em mostrar poder e controle sobre o aparato estatal, embora, em alguns casos, o critério técnico seja relevante ou até prioritário (segurança pública, saúde e fazenda, por exemplo). Aliados ao governador, esses "padrinhos" indicam seus afilhados e a nomeação deles é uma grande demonstração de influência, fator que aumenta seu capital pessoal. Usando os termos de Bourdieu (2005, p. 172), a nomeação de afilhados faz parte das lutas inerentes ao "campo político" e à sua lógica da "oferta e procura", que constitui um exercício estratégico de ocupação do "espaço das tomadas de posição".

Uma das primeiras observações que realizei foi de que esses nomeados possuem a noção de que fazem parte daquilo que designam de a "máquina". É um termo que circula pela imprensa e pela opinião pública. Constitui o conjunto dos servidores, especialmente os comissionados, e as instituições oficiais, reconhecido socialmente por sua capacidade de intervir na sociedade, distribuindo benesses ou punindo os recalcitrantes. Ouvi logo, assim que tomei 
posse, de um secretário de estado, que "a máquina é poderosa". Outro elemento importante que compreendi nessa relação, desde o início (2011), através de conversas que mantive para aprender o funcionamento diário da burocracia, foi de que não é algo negativo "pertencer à máquina". Pelo contrário, os funcionários mais antigos falavam constantemente, inclusive querendo criar uma impressão de autoridade, que "era para ter orgulho". Em termos acadêmicos, pode-se dizer que a máquina política, em termos gerais, caracteriza-se por sua possibilidade de proporcionar privilégios e oportunidades a grupos escolhidos por razões eleitorais, gerando a chance de ganhos econômicos e de status das mais diversas formas. Conforme analistas explicitam, é válido dizer que as "[...] regras de nosso sistema eleitoral incentivam estratégias localistas e distributivistas dos parlamentares" (LOPEZ; PRAÇA, 2015, p. 109). Os mesmos autores acentuam que a distribuição de cargos é um “[...] importante canal de controle sobre a alocação de recursos para bases eleitorais, ainda mais porque as decisões sobre a alocação de recursos são feitas pelo próprio Executivo, conferindo a este grande discricionariedade" (LOPEZ; PRAÇA, 2015, p. 110). Essa máquina pode, conforme os interesses, canalizar seus benefícios para “[...] atores individuais e seu círculo familiar, para grupos de vizinhança ou comunais, ou ainda para uma série de categorias sociais particulares, de natureza funcional, étnica e religiosa" (DINIZ, 1982, p. 29).

Outra coisa que logo ficava clara, sendo abertamente comentada pelos servidores, é que o serviço deveria ser considerado, principalmente, como uma relação de "confiança". Estar ali, em um cargo de relevância e com relativo poder decisório, seria especial. Em uma reunião, em 2015, em plena crise econômica, um secretário disse que poderia falar abertamente dos problemas de orçamento, pois "ali se estava em família e todos eram de confiança". Dialogicamente, esse valor - confiança - era reforçado constantemente, em reuniões ou conversas informais. Aquele que foi nomeado entende que confiam nele e que conseguiu, assim, especialmente por uma relação pessoal, ascender a "um cargo que muitos desejam". Certa vez, vi um secretário repreender um chefe de gabinete, em plena onda de demissões, dizendo que "qualificados como ele havia muitos".

É importante, segundo um conselho, quase em tom de confidência que ouvi, que "não se fique fora do meio, que fique sempre circulando, mostrando que é importante". A relação pessoal, que não é desvinculada do saber técnico necessário ao cargo, seria o eixo central dessa escolha. O elemento afetivo cria vínculos e lealdades. É válido, aqui, se fazer uma referência ao conceito de "clientelismo". Nos estudos políticos, esse termo é usado para definir o tipo de relação personalizante que se efetua dentro de organizações. Pela mediação de um político, cargos de confiança são usados como uma moeda de troca. Os políticos que indicam pessoas 
para os cargos do primeiro ou segundo escalão possuem metas políticas, usando os cargos de que dispõem como um patamar para futuros projetos. Analistas ressaltam, falando sobre os ministros e suas nomeações, como esses atores possuem objetivos, tais como "[...] avançar na carreira, maximizando poder e prestígio futuros [...] e implementar de forma efetiva a agenda do governo" (BORGES; COÊLHO, 2015, p. 75). Assim sendo, a formação das redes dentro da “máquina” é essencial. É dessa forma que as clientelas são construídas dentro das organizações públicas, apesar de sua suposta racionalidade e da alegada exclusividade de critérios técnicos. A proximidade a um político facilitaria o "acesso" (KUSCHINIR, 2000, p. 150) a esse bem inestimável: o cargo. O ponto central estaria na ideia de que há uma troca nessa relação "[...] patronus/cliente. Uma carga mínima de afeto reveste a relação patronus/cliente de confiança, que sublinha a promessa de um apoio mútuo no futuro" (BAHIA, 2003, p. 120). Há uma instabilidade precária nessa situação. A lealdade seria o ponto que torna sólida tal relação. Nos termos clássicos de Mauss (1981, p. 365), “[...] a coisa recebida como dom compromete, liga mágica, religiosa, moral e juridicamente o doador e o donatário".

Pela minha posição, passavam por mim vários pedidos por cargos diariamente. Achava que chegaria um momento em que não mais houvesse vagas. Porém, em uma reunião sobre tais demandas, me foi dito que "sempre havia uma reserva de cargos". Os órgãos precisariam reservar um "espaço para os cargos políticos", conforme circulava pelo primeiro escalão, pois seriam eles (os cargos) que dariam estabilidade e governabilidade. Somente com técnicos sem vínculos políticos, as pressões poderiam desestabilizar os gestores, pois "os pedidos continuariam acontecendo todo dia". Um movimento típico de governos de coalizão, nos quais a governabilidade é um dos valores centrais, zelosos por agradar aos aliados. Assim como o presidencialismo de coalizão ${ }^{2}$ demanda "negociações bem-sucedidas"; para se manter, os governos estaduais seguem a mesma lógica, e é "consensual que a divisão de cargos" (LOPEZ, 2015, p. 17) seja um dos recursos (entre outros, como alocação de verbas) para que essa meta seja alcançada. Um secretário me afirmou, orgulhoso, que "são os cargos que garantem a estabilidade. O governo precisa deles".

Em uma reunião sobre os cargos, em 2013, comentou-se livremente, na hora de decidir se haveria, ou não, mais nomeações, que os concursados acabam "acomodados e sem vontade", por isso seria preciso ter pessoas nomeadas para dar mais agilidade. Dessa forma, atender pedidos por cargos já fazia parte integrante da rotina institucional, conforme acabei

2 Ver ABRANCHES, Sérgio. Presidencialismo de coalizão: o dilema institucional brasileiro. Revista Dados, Rio de Janeiro, v. 31 n. 1, p. 22-70, 1991. 
por compreender "ironicamente" em meus afazeres, após esses diálogos, como algo a ser feito em nome da governabilidade. Os próprios nomeados entenderiam sua presença como parte desse grande "acordo pela governabilidade" (NOBRE, 2013, p. 12), já que eles se veriam como a corporificação das alianças políticas superiores. Na maior parte dos casos, era sinal de status, por parte de um servidor médio, ou mesmo de cargos operacionais, falar que "foi indicado" por alguém poderoso. Era um sinal de que aquela pessoa fazia parte de um sistema maior, cujo funcionamento demandaria a sua presença naquele posto, como consolidação de um pacto não escrito. É o momento em que o governar se personaliza, e as organizações formais e impessoais consolidam sua coesão, virando uma "máquina política". Um nomeado me afirmou, em conversa informal, que "deve tudo a ele (quem o indicou)". Outro nomeado, um secretárioexecutivo, me confidenciou, enfatizando a busca de apoio parlamentar: "a máquina tem de funcionar e só assim (pelas nomeações) é que ela pode agir”. É um processo essencialmente pessoal de troca de interesses que se dá "entre a máquina e o eleitor" (BAHIA, 2003, p. 210). Quem vai concretizar isso na ponta, personalizando as distribuições de benesses, é o detentor do cargo de confiança. Ou mais, é a própria nomeação que simboliza essa troca, que passa a ser vista como um auxílio ou uma até uma obrigação.

Dessa forma, ouvi, em um diálogo sobre a legitimidade dessa rotina, pois estava "surpreso" com a naturalização de tal prática, um secretário-adjunto chegar a dizer que "é natural que seja assim, porque é da política mesmo". Ser parente, cabo eleitoral ou amigo de alguém influente é considerado como algo "natural" nesse momento de escolha de pessoal. Por outro lado, como resposta a esse tipo de opinião, pode-se demarcar que, especialmente nos momentos de crise econômica e/ou política e em algumas áreas de maior especialização (Fazenda, por exemplo), outra argumentação surgia. Assim como as relações de poder são dinâmicas, também o são as "resistências" (FOUCAULT, 1984, p. 91). Alguns secretários enfatizavam que precisavam de "quadros técnicos para tocar o dia a dia". Em situações "dramáticas" de crise ou quando certo impasse técnico se estabelecia (por exemplo, licenciamentos ambientais, questões jurídicas ou estratégias de segurança pública), aparecia o discurso, nos gestores mais graduados, de que "somente os técnicos do governo podem resolver isso". O peso da "especialização rigorosa" (WEBER, 1982, p. 160) teria uma certa "autoridade" diante de alguns dilemas. Para isso, os "técnicos seriam importantes", como um chefe de gabinete me confessou diante de um problema ambiental. É importante remarcar esse acento no aspecto técnico de alguns cargos e carreiras. Se, no início, destaquei uma dicotomia básica entre "permanentes e não permanentes" (concursados e não concursados) é importante destacar, por ora, que outras tensões surgem no desenrolar do tempo, como essa entre "políticos e técnicos". É mais apropriado, assim, falar de 
um hibridismo tenso entre tais posições, pois há técnicos concursados e outros, não concursados, por exemplo. Usando os termos de Marcus (1994, p. 23), poderia dizer que se constrói, assim, um "texto confuso" de tais denominações, conforme a situação e a demanda que se apresentava. Às vezes, predominava o discurso tecnicista. Outras vezes, o imperativo da governabilidade dominava as reuniões e as demandas dos aliados tinham prioridade. Essa dinâmica intertextual não pode ser perdida de vista ao longo de estudos que enfoquem o serviço público.

Logo após o período eleitoral (2011 e 2015), era comum que pessoas fossem à sede do governo, buscando os cargos que, supostamente, seriam seus. A justificativa que ouvi de um desses solicitantes, ao indagar a razão de seu pedido foi que "trabalharam na campanha e receberam a promessa de que era só ir lá e se apresentar”. Mostrar cartões de apresentação ou dizer que eram "da equipe" de algum político seriam formas de fazer jus ao sonhado cargo. Ter "trabalhado na campanha" era um requisito praticamente obrigatório para merecer a nomeação. Carvalho (2000, p. 48) utiliza o termo "razão clientelista" para definir esse movimento de pedidos por empregos no início da República Velha, referindo-se à gestão de Ruy Barbosa. Nas suas palavras, esse "[...] patronato era elemento importante do exercício do poder, esperado pelos favorecidos, aceito pelos que o exerciam" (p. 51).

A confiança e o afeto seriam os valores centrais dessas trocas assimétricas. Uma vez, logo em 2011, indaguei a um ex-secretário, que ainda possuía um cargo no segundo escalão, de origem acadêmica como eu, qual seria o conselho que ele me daria. Sua resposta foi que "a coisa mais importante do serviço público é fazer amigos”. Construir relações pessoais que impliquem obrigações de "retribuir" (MAUSS, 1981, p. 363) seria o centro dessa interatividade. Entretanto, são obrigações assimétricas. Em tom de lamento, ouvi uma funcionária antiga em cargo de assessoria dizer que estava sempre em dívida e se sentia "obrigada a trabalhar", aceitando ir "aonde a mandassem". As nomeações podem ser vistas como atos de "consagração" (BOURDIEU, 2005, p. 166), os quais constroem um mundo, ordenando-o, segundo critérios de "autoridade social" adquiridos. Nesse sentido, palavras como "meritocracia" ou "desempenho" (BARBOSA, 2014) são lidas por outra "gramática" (NUNES, 2003; VIANNA; FARIAS, 2011), por uma linguagem muito particular e que envolve a confiança, o poder e a retribuição, dependendo da situação em que surge.

Nessa "gramática", ter um bom desempenho significa "ir ao trabalho" e "fazer a sua parte", expressões que ouvi de nomeados tentando legitimar suas situações em momentos de dispensas, como 2015. Esses mesmos servidores ressaltavam que há os que faltam e "somem", mas que estariam "errados", pois poderiam "complicar a vida dos padrinhos". Inúmeras vezes, esses nomeados "mal-comportados" eram exonerados. Porém, nas palavras de um funcionário 
mais antigo, ansioso por me mostrar seu conhecimento sobre a máquina, "muitos deles acabam voltando. É só olhar o Diário Oficial". O mesmo funcionário destacava que, dependendo do "poder do padrinho", já se esperava maior ou menor comprometimento do nomeado. É o momento em que, dentro dessa relação clientelística consolidada, que as "hierarquias e assimetrias" (D'AVILA FILHO; JORGE; COELHO, 2004, p. 217) se estabelecem. O campo político se reconfigura, conforme as relações de poder.

Todavia, pude ver que era uma minoria que exorbitava de suas prerrogativas, "exagerando e perdendo os limites". No dia a dia, os servidores de nível médio sentiam precisar demonstrar lealdade e esforço, retribuindo a dádiva com aplicação. Sabiam fazer parte de um campo no qual as barganhas, e a capacidade em "trocar e negociar os benefícios mútuos serão decisivos para os seus resultados" (D’AVILA FILHO; JORGE; COELHO, 2004, p. 217). Entendem que "muitos querem estar ali”, conforme ouvi de uma secretária estadual naquele cargo. Ouvi, também, um secretário-executivo afirmar, em um instante dramático de reformas, que sabem que a "luta por aquela vaga" é grande e que podem "cair" a qualquer momento. Os atores compreendem que o Estado, os partidos e os políticos são grandes empregadores e que o trabalho nas campanhas, a amizade e o parentesco são elementos importantes para se aspirar a um lugar. Entretanto, há toda uma "gramática" a ser seguida e que conforma as ações desses nomeados.

Porém, o foco aqui é acentuar como essa "gramática" do clientelismo, com suas "redes personalistas" (NUNES, 2003, p. 32) opera no cotidiano e como ela é entendida por seus participantes. Assim sendo, um ponto claro desse "saber local" que os nomeados para esses cargos de confiança demonstram conhecer é a importância de "circular, ser visto por todos". Além disso, é vital "saber fazer alguma coisa", possuir algum tipo de habilidade técnica que possa ser utilizada. Tudo isso se soma ao fato de que "é preciso ajudar um companheiro", frase que ouvi muitas vezes, nos momentos de crises e cobranças. As relações pessoais são um elemento central dessa gramática, fato que os atores precisam reafirmar constantemente.

Finalizando este bloco, é importante ressaltar como a relação pessoal entre o patrão e o cliente é essencial para a nomeação. Contudo, o código transversal é o de que os nomeados sabem que "fazem parte da máquina" e que há, também, uma lealdade maior à figura do governador, ao "seu grupo político" e aos interesses macropolíticos da organização estatal. Usando reflexões já consagradas, pode-se dizer que a máquina possuiria uma lógica clientelista, na qual a "manutenção e o recrutamento" (DINIZ, 1982, p. 36) constituem momentos decisivos para seu funcionamento. Lealdades horizontais e verticais se entrecruzam nesse código organizacional. E os seus membros são cobrados para saberem disso. 


\section{A BOCA}

De forma um pouco pejorativa, até mesmo irônica ou cínica, conforme a ocasião, alguns membros dos escalões médios se referiam às suas posições como "a boca". Notei, em conversa informal, que um funcionário mais humilde não compartilhava dessa visão e nem gostava de usar tais termos, pois era receoso de ser "mal interpretados ou parecer ingrato". Porém, esses membros graduados de segundo escalão se viam como parte de algo especial, que suas trajetórias, de forma merecida ou não, como alguns admitiam, levou-os a um lugar que nem todos tinham acesso. Um local de suposta tranquilidade e status. O que manteria um político forte seriam, nos dizeres de um experiente secretário, "os cargos que seria capaz de conseguir". Dessa maneira, brigar por cargos para seus "clientes" seria uma forma de se posicionar nesse campo, mostrar que tem "acesso" (KUSCHNIR, 2000, p. 153) ao Diário Oficial e ao governador.

Entrar no mundo das nomeações, para esse segundo escalão, seria algo que tiraria os indivíduos do mundo comum, fazendo-os "ser parte do governo". A população comum manteria contato com os políticos através de cartas, pedidos e visitas, naquele período que poderia ser chamado de "entre duas eleições" (PALMEIRA; HEREDIA, 2010, p. 95). Contudo, há limites nessa relação, especialmente a distância física até os assessores, que costumam selecionar a maioria das solicitações, apesar do zelo que os políticos dedicam a esse relacionamento com o eleitor (PALMEIRA; HEREDIA, 2010). Todavia, obter uma nomeação seria sair dessa vala comum e chegar a um posto tranquilo, no qual seriam necessários atributos específicos para se "manter vivo", expressão usada por um servidor que "sobreviveu" a várias reformas e crises.

Há uma aura de magia na visão que essas pessoas possuem sobre elas mesmas e sua posição. Primeiro, por terem conseguido esse objetivo, quando muitos fracassaram. Além disso, há outros que sobrevivem há anos, pois pulam de cargos e "sempre conseguem uma boquinha". Mesmo sem explicitar como chegam a certos postos, seus nomes estariam sempre circulando no poder e "acabam sendo nomeados para algum cargo". É interessante pensar, assim, esses indivíduos que sempre obtêm cargos, pelo prisma da "magia" (MAUSS, 1974), sem que os colegas de órgão saibam como. Essas pessoas, conforme o desabafo de um servidor que tinha acabado de ser exonerado, "estão sempre conseguindo ficar em algum cargo". É uma atualização daquele poder mágico que Mauss (1974, p. 63) comenta ao falar sobre a "facilidade que o mágico tem de realizar tudo quanto quer", vivendo do "mistério".

Por outro lado, todos os funcionários de confiança sabem que as relações de poder assimétricas predominam. Há a certeza de que o "qi (quem indica) é forte". Existe um consenso 
mútuo de que aquele universo dos cargos de confiança é regido por "hierarquias e assimetrias de poder" (D’AVILA FILHO, 2003, p. 151). Assim, os mais fortes conseguem coisas que "poucos poderiam entender". O segredo é algo que ritualiza e aumenta a crença em um certo "poder oculto" de quem sempre "frequenta o diário oficial". Como destaca Simmel (2009), havia uma reserva diante dessas pessoas que conseguem se manter indefinidamente em cargos, um sentimento de que se deve respeitar o "segredo do outro [...] que consiste em nos restringir de conhecer todos os fatos da condição do outro que ele não revele" (p. 228). Seguindo a referência de Simmel (2009, p. 235), o segredo implica em ocultar elementos que "não deveriam se produzir na mais completa publicidade". Esse segredo, produz efeitos de mistério que só aumentam as especulações e aquela citada aura de poder que alguns indivíduos possuiriam na máquina. Um assessor, em tom didático, me advertia "que nem todo mundo é igual aqui".

É um jogo de claro/escuro, opaco/transparente, no qual relações de poder assimétricas estão sempre em jogo. Chegar à “boca” implica possuir algo especial, mágico. Manter-se também é fruto de decisões e comportamentos muito especiais. Um certo ethos que esses nomeados incorporam, através de processos de aprendizado, e atualizam cotidianamente. Apesar da aparência de imobilismo e das queixas sobre o patrimonialismo que dominaria as organizações públicas (SENNA, 1995; SCHWARTMAN, 1982; SCHWARCZ, 2019), é essencial ressaltar como elas são dinâmicas e conflituosas, com "níveis hierárquicos múltiplos", o que leva a uma intensa movimentação de pessoas e ações. Se mover nesse universo demanda uma competência própria e elevada habilidade para entender seus códigos.

Nesse sentido, uma queixa foi dirigida àqueles que "nem dão bom dia", pois se acham muito importantes ou com padrinhos extremamente poderosos. É um campo repleto de conflitos, segredos e insinuações. Ter amizades e relacionamentos, sem ser arrogante, é visto como fundamental. Outra crítica que ouvi é dirigida àqueles que são nomeados para cargos melhores e, segundo um servidor ameaçado de demissão, "ficam distantes, esquecendo dos colegas". A amizade pressupõe "confiança e intimidade" (SIMMEL, 2009, p. 231) para que as pessoas possam se ligar. O fato de "esquecer os amigos", depois que se sobe de cargo, é considerado algo negativo. Nesse ambiente dominado pela pessoalidade, no qual a "razão clientelista" é a gramática dominante, ter um amigo em um estrato superior indica novas oportunidades e a possível abertura/acesso de portas antes inviáveis de serem alcançadas. A intimidade e a proximidade física passam a ser elementos essenciais desse universo. Reclamar que o "cara ficou distante", seria comum em situações dramáticas de mudanças na gestão e indicaria que o "padrinho" pode não estar mais preocupado com seu destino, ou que "os amigos não ligam mais" para seu futuro, e que sua posição balança. 
Um importante ponto, que compreendi ao longo desses anos, foi o fato de que os nomeados entendem precisar de "estímulos". É um sistema dinâmico, no qual a percepção de vantagens é fundamental. Um secretário-executivo, com muitos anos de governo, me tentava ensinar que é a "teoria da cenoura: eles ficam balançando uma cenourinha na sua frente, pra você achar que vai se dar bem". O "eles" seriam os mais fortes, os mais poderosos na organização. Deixar as pessoas soltas significaria desleixo, abandonar sua clientela transmitiria insegurança. É preciso assegurar "a lealdade da clientela ao patrão [...] e que o patronus seja visto como detentor do monopólio da distribuição de utilidades" (BAHIA, 2003, p. 337). As promessas de benesses seriam fundamentais, como no lamento de um secretário, de que "já me prometeram que ia viajar pra China, pra tirar passaporte e nada. Tem algo errado". Poderia formular, como pista analítica, para futuros estudos, que esse "afastamento" do padrinho teria relação com o cenário político macro (busca de apoio parlamentar, por exemplo), com crises econômicas (necessidade de enxugar o quadro) ou com reformas administrativas (agilizar a gestão ou ameaças dos órgãos de controle). Além disso, o servidor precisaria mostrar serviço e a condução concebida como ineficiente de projetos no qual os "padrinhos" apostariam muito capital político também seria um fator de distanciamento.

Contudo, esses servidores nomeados não entenderiam que sua colocação em cargos de confiança fosse um problema para o gerenciamento do aparato estatal. Ouvi, em tom de justificativa, durante uma negociação de demandas, ao questionar certos critérios, que "em todo lugar tem isso". Os incentivos seriam um fator importante, na visão de muitos desses servidores, especialmente nesse escalão intermediário, para o sistema funcionar. Um argumento levantado pelos mais antigos, aqueles que atravessaram vários governos, para permanecerem indefinidamente nos cargos, é que "ninguém saberia fazer meu trabalho. Só eu sei como isso funciona". Barbosa (2014, p. 83) assinala como o discurso antimeritocrático existe nas organizações públicas e a "senioridade" é vista como um valor central. Há o que ela chama de "um sentimento de posse em relação à organização" (p. 84). Sentem-se um pouco donos de seus postos. Usando os termos de Holanda (1989, p. 47), é forte a sensação nesses indivíduos de que pertencem a uma "família", que estão vinculados entre si por relações "personalistas" em que os "vínculos biológicos e afetivos unem ao chefe os descendentes, colaterais e afins". Esse "mecanismo social negativo" (BARBOSA, 2003, p. 70) que seria a competição motivada por avaliações traria injustiças, na visão desses agentes, e romperia com aqueles códigos personalistas tão respeitados e valorizados por seus integrantes. Os cargos podem mudar de dono, como veremos adiante, mas a introdução, sem filtros, de critérios impessoais, oriundos de empresas privadas, seria vista como um erro nas crises. Ao comentar o fracasso de um 
secretário e sua exoneração, um servidor antigo assinalou que "o erro foi tentarem implantar coisas de empresas privadas por aqui".

A introdução de critérios de avaliação ou de punição seria introduzir uma desordem nesse universo, cujas regras personalistas já estariam dadas. Seria introduzir a competição em um universo cuja "[...] hierarquia deve ser vista como algo natural e os conflitos tendem a ser tomados como irregularidades" (DAMATTA, 1997, p. 184). Isso é importante, pois o tema da "profissionalização da burocracia" ou da eficiência nos serviços públicos é algo debatido e que está no centro de propostas sobre a gestão pública. Em recente obra, um gestor do IPEA destacava que a "[...] discussão sobre a politização da gestão pública e seus efeitos sobre a qualidade e a eficiência das políticas públicas" (SOUZA, 2015, p. 7) seria vital na análise da relação entre política e técnica na gestão brasileira. Abordar essa autorrepresentação, então, seria essencial para esse processo compreensivo.

Enfim, "entrar na boca" seria um fato importante na vida desses nomeados. Marcaria o ponto de reconhecimento de sua importância, tanto individual como familiar. Isso demonstraria que possuem "alguma importância e não podem ser deixados de lado, jogados na água", como me foi dito logo em 2011, por um servidor que desejava mostrar autoridade. Sua presença na burocracia estatal seria algo normal, que não violaria as regras da impessoalidade ou da eficiência. Isso "faz parte da política". Ou seja, manter uma clientela em moldes patrimoniais dentro das organizações seria intrínseco à política real. A administração técnica, feita exclusivamente por peritos concursados e sem vínculos políticos, seria irreal, como já apontam alguns estudiosos, pois " [...] a arena política contraria a utopia do planejamento como fruto da intervenção puramente técnica do perito" (D’AVILA FILHO; JORGE; COELHO, 2004, p. 214). Os interlocutores possuem a sensação de que tais abstrações jurídicas seriam irreais, pois, como ouvi, em 2012, em reunião sobre o uso de métodos de consultorias privadas, "na administração pública é outra coisa”. Os compromissos entre os líderes, e deles com as comunidades e com os apoiadores teriam de ser retribuídos e reconstruídos cotidianamente. Os cargos seriam uma das moedas dessa negociação incessante.

\section{O MEDO DE PERDER 0 EMPREGO}

Excetuando-se os secretários ou seus assessores mais diretos, cuja dinâmica política envolve aquela aura de "magia e segredo" já citada e que merece outro estudo, a maioria 
(segundo escalão e até os operacionais) sofre com um medo constante: perder o emprego ou, na linguagem peculiar de alguns servidores - "cair da boca".

A qualquer momento um padrinho pode mudar de opinião, um candidato pode perder uma eleição, um órgão ser fechado ou ter seu orçamento reduzido. As mudanças no cenário econômico, as cobranças dos órgãos de controle ou as crises políticas seriam perigos constantes para esse grupo nos cargos de confiança. Mostrar que "é importante" e que seu órgão "faz parte de um projeto importante para o futuro do estado", como ouvi em diálogo com uma servidora preocupada, se torna uma demanda diária. Uma pessoa teria sido exonerada em uma mudança de chefia, "porque não soube ser importante para os novos chefes", como me alertaram em 2015, época de muitas demissões.

No mundo idealizado da burocracia weberiana, certamente que o funcionário possui uma "[...] lealdade moderna dedicada a finalidades impessoais e funcionais" (WEBER, 1982, p. 232). Nesse mundo racional, o "trabalho puramente objetivo e empresarial [...] e o trabalho incansável, continuado e sistemático, bem como a vida metódica" (SCHLUCHTER, 1999, p. 133) constituem a base ética das relações racionais de convívio. Contudo, a observação cotidiana serve para se verificar quais os "conhecimentos locais" que se produzem nesse grupo e como seria vital "desnaturalizar visões de mundo" (TEIXEIRA, 2014, p. 39) consagradas.

Dessa maneira, pode-se ver que vários medos rondam o dia a dia dessas pessoas. É válido, nesse ponto, recuperar esse sentimento - o medo - e "seu valor simbólico", mostrando como "[...] indivíduos, coletividades e civilizações estão em um diálogo permanente com o medo" (DELUMEAU, 1989, p. 12). Usando os termos de Lefebvre (1979, p. 10), pode-se dizer que um "grande medo" percorria os órgãos públicos, quando se pediam as "relações de comissionados". Mudanças de governo (2014) ou reformas (2012, 2015 e 2016) causadas por crises econômicas geravam ondas de boatos de exonerações coletivas. O governador e os secretários pediam listas de comissionados para decidir quem seria demitido. Um assessor contábil, com alguns anos de governo, me afirmou "que é o momento em que alguém vai rodar". Esses seriam momentos "dramáticos", repletos de tensões e conflitos metafóricos (TURNER, 2008), no qual todos buscavam "mostrar trabalho", pois, como uma servidora lamentava, certa de que seria exonerada, em 2015, “essas listas são injustas. Quem não trabalha acaba ficando". Seria vital recorrer aos padrinhos, apesar do sentimento de medo. Além disso, seria a hora de mostrar importância. Um servidor me alertava, em 2016, que "o governo vai parar, se todo mundo for demitido mesmo". Nas palavras de Geertz (1991, p. 84), é um momento dramático no qual se vê que a máquina, longe de ser estável, se ergue como uma "pirâmide de poder periclitante" em que a demissão é um elemento vivo. 
$\mathrm{Na}$ trilha do historiador Georges Lefebvre, a marca desse grande medo das demissões é o boato. Há um momento em que "boato gera boato" (LEFEBVRE, 1979, p. 35) e ninguém sabe mais os limites da verdade e da mentira. Geralmente, os boatos são acompanhados por porcentagens e números, pois se falava, por exemplo, nos corredores da sede, em 2015, auge da crise econômica estadual, que "uns trinta por cento vão ter de sair". Os boatos sobre demissões circulariam livremente nesse "mundo intersubjetivo compartilhado [...] que é um mundo comum a todos nós" (SCHUTZ, 1979, p. 159), como afirma a análise fenomenológica. $\mathrm{O}$ medo e a insegurança seriam constituintes desse universo dos detentores de cargos de confiança, principalmente os de nível médio, sem padrinhos muito fortes. Nesse clima, vale a pena "mostrar serviço, não negar trabalho e estar sempre pronto a ajudar". Essa é a receita que um assessor falou a outro, que estava para ser exonerado. Mostrar comprometimento seria uma saída nesse momento de insegurança. Um erro fatal seria permanecer "acomodado". Um servidor que continuou empregado, após várias exonerações, lembrava que "ninguém queria nada, todo mundo se acomodou. Agora, estão por aí, correndo atrás".

Há momentos em que a competição e a avaliação de desempenho seriam vistas como negativos, que romperiam esse "ambiente comum" (SCHUTZ, 1979, p. 160). Porém, nessa hora de crise, seria vital uma avaliação, pois assim, como um servidor que permanecera dizia: "se veria quem realmente trabalha". É aqui que surge o que chamaria de o "Dilema da Máquina Política", como enunciado por uma antiga secretária em tensa reunião sobre demissões: "o problema é que quem trabalha é que pode ser demitido e quem não trabalha é que não pode ser demitido". O "antigo" aqui significa alguém que ocupa um cargo há mais de dois governos. Essa seria uma marca que consagraria um servidor "que está sempre no governo". Seriam pessoas com elevado "status" e que gozariam de um respeito corporativo, capazes de "ensinar as manhas" do governo, como um deles me falou, de maneira paternalista, ainda em 2012.

Todas as assimetrias e hierarquias aparecem neste instante. Os conflitos e tensões desse campo surgem de forma aberta. Os mais "fortes" buscam seus padrinhos e mostram força, querendo mostrar estarem acima dos boatos. Os mais "fracos" correm para "mostrar serviço" e conclamar algum tipo de justiça, na qual o valor do trabalho retoma seu caráter de dever e responsabilidade, nos dizeres weberianos sobre os "trabalhadores sóbrios, conscientes e incomparavelmente industriosos que se aferraram ao trabalho como uma finalidade de vida desejada por Deus" (WEBER, 1983, p. 127). É uma retomada instrumental e situacional do ethos "puritano", motivada por uma crise e pelo receio de sair.

O medo provoca, naqueles do primeiro e segundo escalão, o sentimento de que é "preciso falar direto com o governador". As mediações clientelistas parecem acabar. A ideia é entrar 
em contato com o centro do poder. Um gestor, após cortes no orçamento, em 2016, decidiu que só iria tomar decisões, “após falar com o número um”. O governador é um ator central nesse jogo, pois tem poder e/ou influência sobre a Assembleia, sobre o Judiciário, a imprensa e, obviamente, o Executivo. Análises políticas chegam a falar em um "ultra-presidencialismo estadual" (ABRUCIO, 1994, p. 173). O controle dos governadores sobre as bases, o orçamento, a opinião pública e os cargos fazem com que "eles tenham uma grande margem de manobra [...] na administração pública" (p. 176). O recurso ao governador - ao "número um” - é visto como uma última chance de se permanecer. Porém, é coisa para poucos e que "não pode ser desperdiçada". O comando da máquina política é do governador, pois é claro para os atores envolvidos que "o controle está centralizado na instância executiva, cerne do processo decisório" (DINIZ, 1982, p. 127). Uma decisão dele pode reverter demissões já fechadas. No momento da negociação das nomeações, é o governador que "dá as cartas do jogo" (ABRUCIO, 1994, p. 177).

Um atraso na resposta do padrinho é visto de forma negativa. Um termo usado por um servidor é que o colega, cujo nome aparecia nas listas de exonerados, apesar dos padrinhos "fortes", está levando "uma barrigada". Notei, então, que os pactos são efêmeros. Nesse nível médio de cargo, os acordos e as dívidas são sempre negociáveis. Ouvi um secretário dizer, após saber que uma servidora estava reclamando muito, que poderia tirá-la, "porque ela já ganhou muito e já está lá há muito tempo”. A “obrigação absoluta de retribuir” (MAUSS, 1974, p. 50) não é eterna. Os conflitos nesse campo são claros. A efemeridade seria uma marca constituinte da subjetividade dos nomeados, conforme as demandas políticas ocasionais. Outros políticos podem querer o cargo, o governador pode decidir pela "extinção de um órgão" ou um órgão de controle pode estar fazendo exigências de cortes. Pode-se dizer que o campo político é, acima de tudo, um campo de "lutas", que "tem em vista transformar a relação de forças" (BOURDIEU, 2005, p. 164). As mudanças são inerentes a ele e as "barrigadas" passam a ser constituintes desses instantes dramáticos. Quando o padrinho não atende mais telefonemas ou responde de forma evasiva às demandas de seus "clientes", é sinal de que algo está errado. Aqui, o servidor entende que "a casa caiu", expressão que ouvi de um demitido em 2014.

Outra forma de "rompimento contratual" ocorre quando essa nomeação é incentivada e envolve algum tipo de parceria maior do patronus com seu cliente. Às vezes, o nomeado é incentivado a gastar dinheiro, adquirir bens e empreender. Sua relação é tão próxima com o líder, que pode planejar construir "empresas duradouras" (WEBER, 1983, p. 6). Porém, por alguma razão inesperada, o líder abandona esse servidor e as dívidas ficam em aberto. Esse é o momento em que ocorre "uma pernada". Por isso, servidores mais antigos recomendam os 
mais novos e "empolgados" a não fazerem dívidas ou não confiarem muito nas promessas, pois "tudo isto aqui pode acabar de repente". A referida efemeridade ameaçaria constantemente os comissionados. A “insegurança” deveria servir como um guia para as ações desses servidores, segundo opiniões de alguns funcionários mais experientes. Compreender a efemeridade tensa de seu posto é essencial nessa gramática. É o remédio contra as “pernadas" e uma possível falência do servidor que fez planos de longo prazo.

Para finalizar esta seção, creio ser relevante ressalvar que todo esse sistema é dinâmico. Vários códigos o atravessam. Seria melhor falar em uma "combinação de gramáticas" (NUNES, 2003 , p. 112) do que em um simples modelo patrimonialista ou clientelista. O servidor que se orgulha de ter sido nomeado por suas relações pessoais é o mesmo que busca "mostrar serviço" nos momentos dramáticos de perigo e crise. O trabalho e a justiça são valores instrumentais e localizados, usados conforme a conveniência e o instante. Rompimentos de pactos não jurídicos são constantes. A insegurança e o medo da perda do cargo, com suas respectivas quedas de remuneração e de status, são elementos presentes no cotidiano desses atores. A máquina vive e se alimenta dessas linguagens e de suas tensões.

\section{CONCLUSÃO}

Enxergar uma organização pública pelo viés de seus servidores, em especial aqueles com certos cargos de confiança, requer considerar que esse grupo analisado possui um "saber" peculiar e que seus códigos podem ser transcritos e compreendidos. São um "outro" que está bem próximo de nós, nas repartições ou nos noticiários, mas "não é necessariamente conhecido" (VELHO, 2008, p. 126).

As discussões sobre reforma administrativa, que ganharam ânimo desde os anos 90, são necessárias. Debater o modelo estatal de gestão é relevante para um Brasil cuja agenda social, política e econômica está em permanente incompletude. O Estado é um ator central da agenda brasileira. Suas ações são protagonistas de nossos rumos. Reformar o Estado é, assim, adaptá-lo "aos desafios do mundo contemporâneo" (CARDOSO, 2003, p. 15) que impactam decisivamente com o país. É comum, então, desde os anos 90, se falar que o Estado vive em crise e que necessita de uma reforma. Uma crise "[...] do modo de intervenção do Estado e crise da forma burocrática pela qual o Estado é administrado" (PEREIRA, 1996, p. 270).

Entretanto, há uma linha de argumentação nesse debate que se prioriza os modelos 
de gestão - burocrático, patrimonial, gerencial - que possam conferir maior eficiência e produtividade às organizações públicas (PEREIRA, 1996; SPINK; PEREIRA, 2003; OSBORNE; GAEBLER, 1992). Indo por outro caminho, este estudo buscou recuperar a dimensão simbólica, cotidiana e vivida dessas organizações, entendendo que reformar o Estado implica também compreender "mentalidades" e "alterar práticas enraizadas" (CARDOSO, 2003, p. 16). Para isso, o entendimento é de que isso apenas será possível, caso entendamos de forma "densa" e "semiótica" (GEERTZ, 2015) a cultura desses homens e mulheres de carne e osso, essa "lógica social e sensual" (WACQUANT, 2002, p. 20) que constrói a administração pública. Por isso, a busca pela "contextualização", que interpretasse e traduzisse o diálogo presente no trabalho de campo (PEIRANO, 2008, p. 8) com esse público específico. Dessa forma, procurei "penetrar na própria medula do governo" (GEERTZ, 1991, p. 89), com o propósito de compreender tais dinâmicas.

Houve a preocupação de não reclamar dos entraves "patrimonialistas" (SCHWARCZ, 2019, p. 64) à modernização brasileira. O artigo buscou compreender, de forma exploratória, a construção cotidiana desse "saber local" de um segmento dos funcionários de um governo estadual, durante certo período (2011-2016) em que estive presente em cargos de gestão. Através de uma etnografia que interpretasse e reelaborasse o que foi dialogado e vivido, sem esquecer o meu próprio posicionamento hierárquico, busquei averiguar atitudes, sentimentos e expressões que pudessem montar um painel exploratório (dinâmico, ressalte-se) de seu cotidiano. Seguindo a antropóloga Mariza Peirano, quis realizar um estudo que pudesse "contradizer, reformular, repensar as categorias de nosso senso-comum” (PEIRANO, 2008, p. 19), questionando aquelas queixas genéricas que o funcionalismo sofre, inclusive da academia (patrimonialista, clientelista, ineficiente etc.). Desconstruir tais termos, vendo como os atores constroem suas concepções, sem esquecer a reflexividade inerente ao meu lugar, foi uma das ambições do estudo.

Assim, o artigo foi uma tentativa de adensar esse debate sobre o papel do Estado no Brasil, analisando a mentalidade dos seus servidores no seu cotidiano. Pode-se dizer, quando se fala sobre a relação entre as instituições estatais e os indivíduos que as compõem, que "o funcionamento das instituições não pode depender da boa vontade de quem trabalha nelas" (PRZEWORSKI, 2003, p. 40). A questão tratada aqui foi exatamente interpretar os significados, os símbolos e os sentidos explicitados em algumas situações e dramas que os nomeados para certos cargos de confiança vivenciam em sua prática. Tais dilemas serviram como pistas para uma possível interpretação densa que complexifique os debates sobre a "cultura organizacional" dos servidores ou a "legalidade" das nomeações e o papel dos concursos, temas marcados pela visão jurídica. Sobre os concursos, ressalto a análise de Maia (2019) e a 
mentalidade dos concurseiros, desejosos de entrar no Estado e assumir cargos de elevado status burocrático bacharelesco, assim se tornando "merecedores de certos privilégios" (p. 220). Um desdobramento interessante desta pesquisa seria comparar essa visão de "merecimento" dos nomeados com aquela dos "concursados". Descobrir esse "estranho", tão próximo e tão longe, colocando-se no "lugar do outro" (VELHO, 2008, p. 127), pode verticalizar concepções. É uma forma de criar um diferente olhar sobre essa questão, abordando-a pela voz de seus agentes, suas ambições e receios.

Para finalizar, ensaiando algumas considerações, pode-se dizer que a questão do poder na dinâmica do funcionalismo é essencial. A tensão estabilidade/insegurança marca o cotidiano desse público nomeado e não concursado. A relação entre os padrinhos e os clientes também é central. A busca de ampliar o apoio parlamentar ou as crises econômicas são fatores gerais que interferem diretamente na "máquina". Pensar eficiência ou produtividade desconectando-as desse cenário maior é enganoso. A relação entre cargos técnicos e políticos deve ser vista de forma relativizada. Há várias instâncias cruzadas que permitem pensar esse universo de forma não binária. Nesse intuito ensaístico e introdutório, vale a pena ressalvar como o afastamento/proximidade do padrinho interfere no desempenho dos seus nomeados, fator que toca diretamente na temática da eficiência. Outro ponto a destacar é como a relação impessoalidade/personalismo é situacional, os discursos oscilando em ziguezague, conforme as vontades políticas se modificam. A simples oposição modernidade versus patrimonialismo não dá conta desse cotidiano nem da forma como as relações pessoais - e de poder - constroem as organizações. Da mesma forma, termos tratados tradicionalmente de maneira "negativa" (clientelismo, por exemplo) vistos como "atrasos", poderiam ser repensados por um viés distinto, através do olhar da necessidade de se equilibrar a adequação técnica a um cargo com o devido direcionamento político, evitando-se maniqueísmos. Enfim, são pistas para futuros estudos que são lançadas, mais como problemas do que como respostas.

\section{REFERÊNCIAS}

1. ABRUCIO, Fernando. Os barões da federação. Revista Lua Nova, São Paulo, n. 33, p. 165-190, 1994.

2. AUGÉ, Marc. O antropólogo e o mundo global. Tradução Francisco Moraes. Petrópolis: Vozes, 2014. 
3. BAHIA, Luiz Henrique Nunes. O poder do clientelismo. Rio de Janeiro: Renovar, 2003.

4. BARBOSA, Lívia. Meritocracia e sociedade brasileira. Revista de Administração de Empresas, São Paulo, v. 54, n. 1, p. 80-85, 2014.

5. BARBOSA, Lívia. Igualdade e meritocracia. Rio de Janeiro: Editora FGV, 2003.

6. BEVILAQUA, Ciméa. Antropologia do Estado: algumas notas metodológicas e éticas. Revista Campos, Curitiba, v. 3, p. 51-64, 2003.

7. BEZERRA, Marcos Otávio. Em nome das bases. Rio de Janeiro: Relume Dumará, 1999.

8. BORGES, André; COÊLHO, Denilson. O preenchimento de cargos da burocracia pública federal no presidencialismo de coalizão brasileiro. In: LOPEZ, Felix. (org.). Cargos de confiança no presidencialismo de coalizão brasileiro. Brasília: IPEA, 2015.

9. BOURDIEU, Pierre. O poder simbólico. Tradução Fernando Tomaz. Rio de Janeiro: Bertrand Brasil, 2005.

10. BRANDÃO, Geyziara. Amazonino Mendes herdará exército de cinco mil comissionados no Estado. Acrítica.com, Manaus, 03 de set. de 2017. Disponível em: https://www. acritica.com/channels/manaus/news/amazonino-mendes-herdara-exercito-de-cincomil-comissionados-no-estado. Acesso em 14 out. 2017.

11. BRONZ, Deborah. Experiências e contradições na etnografia de práticas empresariais. In: CASTILHO, Sérgio Ricardo; LIMA, Antônio Carlos de Souza; TEIXEIRA, Carla. (org.). Antropologia das práticas de poder: reflexões etnográficas entre burocratas, elites e corporações. Rio de Janeiro: Contra Capa, 2014.

12. CARDOSO, Fernando Henrique. Reforma do Estado. In: SPINK, Peter; PEREIRA, Luiz Carlos Bresser. (org.). Reforma do Estado e administração gerencial. Rio de Janeiro: Editora FGV, 2003.

13. CARVALHO, José Murilo de. Rui Barbosa e a razão clientelista. Revista Dados, Rio de Janeiro, v. 43, n. 1, p. 42-68, 2000.

14. CHAVES, Christine. Festas da política. Rio de Janeiro: Relume-Dumará, 2003.

15. CLIFFORD, James. A experiência etnográfica. Tradução Rio de Janeiro: Editora UFRJ, 2008.

16. DAMATTA, Roberto. A casa e a rua. São Paulo: Brasiliense, 1985.

17. DAMATTA, Roberto. Carnavais, malandros e heróis. Rio de Janeiro: Rocco, 1997.

18. D’AVILA FILHO, Paulo. O clientelismo como gramática universal. Revista Physis, Rio de Janeiro, v. 13, n. 2, p. 149-160, 2003. 
19. D’AVILA FILHO, Paulo; JORGE, Vladimyr Lombardo; COELHO, Ana Fernanda. Acesso ao poder: clientelismo e democracia participativa; descontruindo uma dicotomia. Revista Civitas, Porto Alegre, v. 4, n. 2, p. 211-233, 2004.

20. DELUMEAU, Jean. História do medo no Ocidente. Tradução Heloisa Jahn. São Paulo: Companhia das Letras, 1989.

21. DINIZ, Eli. Voto e máquina política. Rio de Janeiro: Paz e Terra, 1982.

22. FARIAS, Orlando. A dança dos botos e outros mamíferos do poder. Manaus: Valer, 2010.

23. FERREIRA, Mariana Carnaes. O clientelismo e os cargos comissionados: impacto na eficiência da administração pública. Academia Brasileira de Direito do Estado, São Paulo, 2014. Disponível em: www.abdet.com.br. Acesso em: 15 out. 2017.

24. FOUCAULT, Michel. História da sexualidade. Tradução J. A. Guilhon de Albuquerque. Rio de Janeiro: Graal,1984.

25. FOUCAULT, Michel. A verdade e as formas jurídicas. Tradução Roberto Machado e Eduardo Jardim. Rio de Janeiro: Nau, 1999.

26. GEERTZ, Clifford. Negara. Tradução Miguel Vale de Almeida. Lisboa: Difel, 1991.

27. GEERTZ, Clifford. O saber local. Tradução Vera Joscelyne. Petrópolis: Vozes, 2013.

28. GEERTZ, Clifford. A interpretação das culturas. Tradução Fanny Wrobel. Rio de Janeiro: LTC, 2015.

29. GOLDMANN, Márcio. Alteridade e experiência. Antropologia e teoria etnográfica. Revista Etnográfica, Lisboa, n. 1, p. 159-173, 2006.

30. HOLANDA, Sérgio Buarque de. Raízes do Brasil. Rio de Janeiro: José Olympyo, 1989.

31. KUSCHNIR, Karina. O cotidiano da política. Rio de Janeiro: Relume Dumará, 2000.

32. LEAL, Victor Nunes. Coronelismo, enxada e voto. São Paulo: Companhia das Letras, 2012.

33. LEFEBVRE, Georges. O grande medo de 1789. Tradução Carlos Eduardo Castro Leal. Rio de Janeiro: Campus, 1979.

34. LOPEZ, Felix. Introdução. In: LOPEZ, Felix. (org.). Cargos de confiança no presidencialismo de coalizão brasileiro. Brasília: IPEA, 2015.

35. LOPEZ, Felix; PRAÇA, Sérgio. Critérios e lógicas de nomeação para o alto escalão da burocracia federal brasileira. In: LOPEZ, Felix. (org.). Cargos de confiança no presidencialismo de coalizão brasileiro. Brasília: IPEA, 2015.

36. MAIA, Bóris. Sujeitos de Estado: Aprendizado e tradição de conhecimento na 
preparação para concursos públicos da burocracia fiscal. 2019. Tese (Doutorado em Antropologia) - Programa de Pós-Graduação em Antropologia, Universidade Federal Fluminense, Niterói, 2019.

37. MARCUS, George. O que vem (logo) depois do pós: o caso da etnografia. Revista de Antropologia, São Paulo, v. 37, p. 7-34, 1994. Disponível em: http://www.jstor.org/ stable/41616138. Acesso em: 26 abr. 2020.

38. MAUSS, Marcel. Ensaios de Sociologia. Tradução Jacob Guinsburg. São Paulo: Perspectiva, 1981.

39. MAUSS, Marcel. Sociologia e Antropologia. Tradução Paulo Neves. São Paulo: EPU, 1974.

40. NOBRE, Marcos. Imobilismo em movimento. São Paulo: Companhia das Letras, 2013.

41. NUNES, Édson. A gramática política do Brasil. Rio de Janeiro: Jorge Zahar Editor, 2003.

42. OSBORNE, David; GAEBLER, Ted. Reinventando o governo. Tradução Sérgio Bath. Brasília: MH Comunicação, 1992.

43. PALMEIRA, Moacir; HEREDIA, Beatriz. Política ambígua. Rio de Janeiro: Relume Dumará, 2010.

44. PEIRANO, Mariza. Etnografia, ou a teoria vivida. Ponto Urbe, São Paulo, 2008. Disponível em: http://journals.openedition.org/pontourbe/1890. Acesso em: $27 \mathrm{abr}$. 2020.

45. PEREIRA, Luiz Carlos Bresser. Crise econômica e reforma do Estado no Brasil. São Paulo: Ed. 34, 1996.

46. PIRES, José Calixto de Souza; MACÊDO, Kátia Barbosa. Cultura organizacional em organizações públicas no Brasil. Revista de Administração Pública, Rio de Janeiro, v. 40, n. 1, p.81-105, 2006.

47. PRZEWORSKY, Adam. Sobre o desenho do Estado: uma perspectiva agents $\mathrm{x}$ principal. In: SPINK, Peter; Pereira, Luiz Carlos Bresser. (org.). Reforma do Estado e administração gerencial. Rio de Janeiro: Editora FGV, 2003.

48. SCHLUCHTER, Wolfgang. A origem do modo de vida burguês. 1999. In: SOUZA, Jessé. (org.). O malandro e o protestante. Brasília: Universidade de Brasília, 1999.

49. SCHUTZ, Alfred. Fenomenologia e relações sociais. Tradução Angela Melin. Rio de Janeiro: Zahar, 1979.

50. SCHWARCZ, Lilia Moritz. Sobre o autoritarismo brasileiro. São Paulo: Companhia das Letras, 2019.

51. SCHWARTZMAN, Simon. Bases do autoritarismo brasileiro. Brasília: Universidade 
de Brasília, 1982.

52. SENNA, José Júlio. Os parceiros do rei. Rio de Janeiro: Topbooks, 1995.

53. SILVA, Margarida da. Trabalhar e investigar enquanto antropóloga na administração pública: breves considerações ético-metodológicas. In: CASTILHO, Sérgio Ricardo; LIMA, Antônio Carlos de Souza; TEIXEIRA, Carla. (org.). Antropologia das práticas de poder: reflexões etnográficas entre burocratas, elites e corporações. Rio de Janeiro: Contra Capa, 2014.

54. SIMMEL, Georg. Sociologia. Tradução Carlos Alberto Pavanelli. São Paulo: Ática. 1983.

55. SIMMEL, Georg. A sociologia do segredo e das sociedades secretas. Revista de Ciências Humanas, Tradução Simone Maldonado. Florianópolis, v. 43, n. 1, p. 219242, 2009.

56. SOARES, Luiz Eduardo. Meu casaco de general. São Paulo: Companhia das Letras, 2000 .

57. SOUZA, Jessé. Apresentação. In: LOPEZ, Felix. (org.). Cargos de confiança no presidencialismo de coalizão brasileiro. Brasília: IPEA, 2015.

58. SPINK, Peter; PEREIRA, Luiz Carlos Bresser. (org.). Reforma do Estado e administração gerencial. Rio de Janeiro: Editora FGV, 2003.

59. TEIXEIRA, Carla. Pesquisando instâncias estatais. In: CASTILHO, Sérgio Ricardo; LIMA, Antônio Carlos de Souza; TEIXEIRA, Carla. (org.). Antropologia das práticas de poder: reflexões etnográficas entre burocratas, elites e corporações. Rio de Janeiro: Contra Capa, 2014.

60. TURNER, Victor. Dramas, campos e metáforas. Tradução Fabiano Morais. Niterói: EdUFF, 2008.

61. VIANNA, Adriana; FARIAS, Juliana. A guerra das mães: dor e política em situações de violência institucional. Cadernos Pagu, São Paulo, n. 37, p. 79-116, 2011.

62. WACQUANT, Loic. Corpo e alma. Tradução Ângela Ramalho. Rio de Janeiro: Relume Dumará, 2002.

63. WEBER, Max. Ensaios de Sociologia. Tradução Waltensir Dutra. Rio de Janeiro: Guanabara, 1982.

64. WEBER, Max. A ética protestante e o espírito do capitalismo. Tradução Irene Szmrecsányl. São Paulo: Pioneira, 1983.

65. WHYTE, William Foote. Sociedade de esquina. Tradução Maria Lúcia de Oliveira. Rio de Janeiro: Jorge Zahar Editor, 2005.

66. VELHO, Gilberto. Individualismo e cultura. Rio de Janeiro: Jorge Zahar Editor, 2008. 


\section{Gilson Gil}

Doutor em Sociologia pelo Instituto Universitário de Pesquisas do Rio de Janeiro, Mestre em Sociologia pelo Instituto Universitário de Pesquisas do Rio de Janeiro, Mestre em Filosofia pela Pontifícia Universidade Católica do Rio de Janeiro, Graduação em História pela Pontifícia Universidade Católica do Rio de Janeiro. Professor Associado da Universidade Federal do Amazonas. ID ORCID: http://orcid.org/0000-0002-8634-5995. E-mail:gilpolitica@gmail.com. 